Pak. J. Agri. Sci., Vol. 53(3),551-556;2016

ISSN (Print) 0552-9034, ISSN (Online) 2076-0906

DOI: 10.21162/PAKJAS/16.1525

http://www.pakjas.com.pk

\title{
MATHEMATICAL MODELING OF BIOPROCESS VARIABLES FOR IMPROVED PRODUCTION OF RHAMNOLIPID FROM Pesudomonas aeruginosa STRAIN JQ
}

\author{
Asif Jamal ${ }^{1, *}$, Muhammad Zahid Qureshi ${ }^{2}$, Raja Razi ul Hussnain ${ }^{3}$, Naeem Ali ${ }^{1}$ and Muhammad \\ Ishtiaq Ali ${ }^{1}$
}

\author{
${ }^{1}$ Department of Microbiology, Quaid-I-Azam University, Islamabad, Pakistan. ${ }^{2}$ Department of Chemistry, GC \\ University, Lahore, Pakistan; ${ }^{3}$ Pakistan Science Foundation, Constitution Avenue G-5/2, Islamabad, Pakistan; \\ "Corresponding author's e-mail: asifjamal@qau.edu.com
}

\begin{abstract}
Recent developments and experimental methodologies have sparked an interest in exploring multifaceted nature of surfactants of biological origin. Rapidly accumulating scientific data is emphasizing on the extensive nature of the biosurfactants produced by various microbial strains having a wider spectrum of biological activities. Confluence of information also provided evidence about the role of rhamnolipid in the development of sustainable agriculture and soil remediation. In present research an environmental isolate of Pseudomonas aeruginosa JQ was evaluated for rhamnolipid production under the effect of some nutritional parameters. Four nutritional factors were investigated viz $\mathrm{NaNO}_{3}, \mathrm{KH}_{2} \mathrm{PO}_{4}, \mathrm{MgSO}_{4}$ and $\mathrm{FeSO}_{4}$ by the application of response surface methodology. On the basis of regression analysis, $3.92 \mathrm{~g} / \mathrm{L} \mathrm{NaNO}, 2.38 \mathrm{~g} / \mathrm{L} \mathrm{KH}_{2} \mathrm{PO}_{4}, 0.26 \mathrm{~g} / \mathrm{L} \mathrm{MgSO} 4$ and $0.0028 \mathrm{~g} / \mathrm{L}$ of $\mathrm{FeSO}_{4}$ were found to be optimum nutritional conditions where $5.67 \mathrm{~g} / \mathrm{L}$ of the rhamnolipid was produced. In conclusion, $P$. aeruginosa JQ showed excellent metabolic potential to produce biosurfactants that could be effectively used in agriculture, environmental and medical applications.
\end{abstract}

Keywords: Biosurfactants, Rhamnolipids, response surface methodology, P. aeruginosa

\section{INTRODUCTION}

Surfactants are one of the most important products of the chemical industry for being extensively used in a wide variety of agrochemical formulations including growth promoters, insecticides, herbicides and fungicides (Deleu and Paquot, 2004). Beside, their wide ranging implications, synthetic surfactants pose serious environmental and health challenges (Burns et al., 2013). In compliance with current environmental legislation, use of sustainable chemicals in agriculture and agrochemical industries has been considerably evoked. Biosurfactants are among those natural products that have gained substantial scientific attraction due of their potential role in agriculture, pharmaceutical, cosmetics and environmental remediation (Das et al., 2010). Chemically, biosurfactants are characterized as glycolipids, lipopeptides, lipoproteins, lipopolysachrides-protein and polysachrides-protein-fatty acid complexes (Cameotra et al., 2010). Considering the performance of biosurfactants as an alternative to synthetic homologies, they have several advantages, including their high substrate specificity, less toxicity, biodegradability, durability at extreme operational conditions and ease of production using renewable resources (Banat et al., 2010; Silva et al., 2014). Biosurfactants can be produced by wide variety of microorganisms found in different ecological habitats. In soil, production of these biomolecules have been known to facilitate plant-microbe interactions, bioavailability of nutrients for beneficial microbes, elimination of pathogens, and improving soil quality (Sachdev and Cameotra, 2013; Yan et al., 2014).

The gylcolipids containing L-rhamnose and $\beta$ hydroxyalkanoic acid moieties are termed as rhamnolipids (RLs). They are characterized as the most effective class of biosurfactants mainly produced by different strains of Pseudomonas aeruginosa under limited growth conditions (Chen et al., 2007). The physiochemical properties associated with rhamnolipid enable these to be exploited in wide variety of applications. In agriculture, they are very effective in improving the quality of agriculture soil by removing organic and inorganic pollutants (PacwaPlociniczak et al., 2011). Similarly, their excellent antimicrobial activity against variety of plant pathogens engraves a place of themselves as an effective biocontrol agent. Moreover, accumulating information has substantiated its role and efficacy as compared to commercial pesticides for controlling resistant plant pathogens (Sha et al., 2011; Krzyzanowska et al., 2012). Rhamnolipids are also involved in improving plant immunity and growth thus naturally reducing plant infections (Vatsa et al., 2010). Their production in the rhizosphare facilitates establishment of biofilm thereby, improving plant microbe interactions and enhance bioavailability of hydrophobic compounds (Ron and Rosenberg, 2011; Gudina et al., 2015). 
The synthesis of rhamnolipids in $P$. aeruginosa is an intricate metabolic process involving a number of physiochemical factors such as carbon substrates, nitrogen source, multivalent ions, $\mathrm{pH}$, temperature, agitation and feeding rate (Nitschke et al., 2005; Kumar et al., 2012). Therefore, optimization of rate limiting factors typically media components have been considered crucial for improved rhamnolipid yield (Gilmour et al., 2006). Statistical design strategies, particularly related to response surface methodology (RSM) are becoming more useful tool in improving the targeted efficiencies of rhamnolipid bioprocess. RSM is an effective statistical technique used for designing experiments, building models, evaluating process variables, and probing minor reaction conditions pertaining to maximum yield of cellular products (Kammoun et al., 2008).

Recently, it has been recognized that self assembly of rhmanolipid monomers generate variety of potent microstructures that could possibly expand their role in various novel applications (Kiran et al., 2011). This has catalyzed a renewed interest in rhamnolipid production and applications. However, current wide spread applications of rhamnolipid are impeded owing to their low cellular productivity and cost of fermentation media. Realizing the future potential of these biomolecules, efforts are underway to improve rhamnolipid production rate by focusing on different nutritional parameters. Therefore, present research is riveted to stimulate the production of rhamnolipids from an indigenous isolate of $P$. aeruginosa by optimization of four critical nutritional factors viz., $\mathrm{NaNO}_{3}, \mathrm{KH}_{2} \mathrm{PO}_{4}$, $\mathrm{MgSO}_{4}$ and $\mathrm{FeSO}_{4}$ using response surface methodology.

\section{MATERIALS AND METHODS}

Microorganism: P. aeruginosa strain JQ was originally isolated from crude oil contaminated soil and characterized for the production of rhamnolipid mixture. The strain was collected from Biochemistry Lab, G.C University, Lahore. The strain was sub-cultured on nutrient agar plates used in subsequent experiments.

Media and inoculum preparation: The basal media with the following compositing $(\mathrm{g} / \mathrm{L})$ was used for the inoculum preparation: $\mathrm{NaNO}_{3} 5 \mathrm{~g}, \mathrm{~K}_{2} \mathrm{PHO}_{4} 3 \mathrm{~g}, \mathrm{NaH}_{2} \mathrm{PO}_{4} 2 \mathrm{~g}$, $\mathrm{MgSO}_{4} .7 \mathrm{H}_{2} \mathrm{O} 0.4 \mathrm{~g}, \mathrm{FeSO}_{4} 0.004 \mathrm{~g}$ and $3 \%$ of glycerol was added as sole source of carbon. The concentration of these salts was changed according to the experimental design. This medium was fortified by adding $1 \mathrm{ml}$ of micronutrients' solution containing; $\mathrm{ZnSO}_{4} \times 7 \mathrm{H}_{2} \mathrm{O}, \mathrm{CuSO}_{4} \times 5 \mathrm{H}_{2} \mathrm{O}, \mathrm{CoCl}_{2} \mathrm{x}$ $6 \mathrm{H}_{2} \mathrm{O}, \mathrm{NaMoO}_{4} \times \mathrm{H}_{2} \mathrm{O}, \mathrm{MnSO}_{4} \times \mathrm{H}_{2} \mathrm{O}$, and $\mathrm{KCl}$. The $\mathrm{pH}$ of the medium was adjusted at 7 and after sterilization $2.8 \%$ inoculum was added into $250 \mathrm{ml}$ flasks which were kept under continuous shaking at $160 \mathrm{rpm}$ and $34^{\circ} \mathrm{C}$.

Rhamnolipids estimation: The estimation of rhamnolipid was carried out by the method of Chandrasekaran and Be-
Miller (1980). Briefly, $333 \mu$ of the culture supernatant was taken and extracted using diethyl ether. The organic phase was extracted in triplicate followed by the evaporation of the solvent. The resultant material was mixed with $0.5 \mu \mathrm{L}$ deionized water. One hundred (100) $\mu \mathrm{L}$ of this mixture was then treated with freshly prepared Orcinol reagent and allowed to react at $80^{\circ} \mathrm{C}$ for $30 \mathrm{~min}$. After cooling the reaction mixture at room temperature, the absorbance was measured at $421 \mathrm{~nm}$ using Spectorphotometer. The results were then analyzed by comparison with a standard curve of the L-rhamnose.

Design of experiment and statistical analysis: Central Composite Design (CCD) strategy was employed in order to formulate an empirical model to determine optimum values of four nutritional factors viz, $\mathrm{NaNO}_{3}, \mathrm{KH}_{2} \mathrm{PO}_{4}, \mathrm{MgSO}_{4}$ and $\mathrm{FeSO}_{4}$ influencing rhamnolipid production A full length factorial design was generated with 30 experimental runs using MiniTab.15 software. Concentration of rhamnolipid $(\mathrm{g} / \mathrm{L})$ was selected as response $\left(\mathrm{Y}_{1}\right)$ to probe the effect of aforementioned parameters. The process variables and their respective levels are presented in Table. 1 and layout of the central composite design including values of response $\left(\mathrm{Y}_{1}\right)$ are expressed in the Table 2 . The results obtained after experimentation were subjected for analysis of variance (ANOVA) to validate the accuracy of observations and possible role of each parameter. In addition, multiple regression analysis was applied to find out linear and quadratic effect of these process variables. The interaction of variables in the given system was explained by the following quadratic polynomial equation:

$\begin{aligned} \hat{Y}=b 0+b_{1} X_{1}+b_{2} X_{2}+b_{3} X_{3}+ & b_{11} X_{21}+b_{22} X_{22}+b_{33} X_{23} \\ & +b_{12} X_{1} X_{2}+b_{13} X_{1} X_{3}+b_{23} X_{2} X_{3}\end{aligned}$

Where $\hat{Y}$ refers to the predicted response and $X_{1}, X_{2}, X_{3}$ and $\mathrm{X}_{4}$ are the coded variables. The term $b 0$ corresponds to the intercept, whereas, $b_{1}, b_{2}, b_{3}$ and $\mathrm{b}_{4}$ represents linear effects, $b_{11}, b_{22}, b_{33}$, and $\mathrm{b}_{44}$ denote squared effects, and $b_{12}, b_{23}, b_{13}$ interaction terms.

The 3-D response surface plots were made using trial version of MiniTab 15 to describe individual and cumulative effects of the process variables.

Table 1. Factors with their respective levels.

\begin{tabular}{|l|l|l|l|l|l|l|}
\hline Variables & \multirow{2}{*}{ Codes } & \multicolumn{6}{|c|}{ Levels of the Variables (g/L) } \\
\cline { 3 - 7 } & & $-\mathbf{2}$ & $\mathbf{1 -}$ & $\mathbf{0}$ & $\mathbf{+ 1}$ & $\mathbf{+ 2}$ \\
\hline $\mathrm{NaNO}_{3}$ & $\mathrm{~A}$ & 0 & 1 & 3 & 5 & 7 \\
$\mathrm{KH}_{2} \mathrm{PO}_{4}$ & B & 0 & 1 & 2 & 3 & 4 \\
\hline $\mathrm{MgSO}_{4}$ & $\mathrm{C}$ & 0 & 0.1 & 0.3 & 0.5 & 0.7 \\
\hline $\mathrm{FeSO}_{4}$ & D & 0 & 0.001 & 0.003 & 0.005 & 0.007 \\
\hline
\end{tabular}

\section{RESULTS AND DISCUSSION}

Process economics has always been the major concern associated with most of the biotechnological products. The 
effect of four media components on the production of rhamnolipid was studied using a full length central composite design consisting of 30 experiments. Second order polynomial equation was generated to describe possible role of independent process variables on rhamnolipid production.

Table 2. Experimental Design and Results of Central Composite Design (CCD).

\begin{tabular}{|l|c|c|c|c|c|}
\hline Runs & $\mathbf{N a N O}_{\mathbf{3}}$ & $\mathbf{K H}_{\mathbf{2}} \mathbf{P O}_{\mathbf{4}}$ & $\mathbf{M g S O}_{\mathbf{4}}$ & $\mathbf{F e S O}_{\mathbf{4}}$ & Rhamnolipid \\
\hline & $\mathbf{X}_{\mathbf{1}}$ & $\mathbf{X}_{\mathbf{2}}$ & $\mathbf{X}_{\mathbf{3}}$ & $\mathbf{X}_{\mathbf{4}}$ & $\mathbf{Y}_{\mathbf{1}}$ \\
\hline 1 & 5 & 1 & 0.1 & 0.005 & 2.31 \\
\hline 2 & 1 & 3 & 0.1 & 0.005 & 1.99 \\
\hline 3 & 5 & 3 & 0.5 & 0.001 & 2.87 \\
\hline 4 & 5 & 3 & 0.1 & 0.005 & 3.24 \\
\hline 5 & 1 & 1 & 0.5 & 0.005 & 1.05 \\
\hline 6 & 5 & 3 & 0.1 & 0.001 & 3.67 \\
\hline 7 & 1 & 3 & 0.1 & 0.001 & 2.16 \\
\hline 8 & 3 & 2 & 0.3 & 0.003 & 4.52 \\
\hline 9 & 1 & 1 & 0.1 & 0.001 & 0.88 \\
\hline 10 & 3 & 0 & 0.3 & 0.003 & 0.23 \\
\hline 11 & 3 & 2 & 0.3 & 0.003 & 4.61 \\
\hline 12 & 1 & 1 & 0.5 & 0.001 & 1.12 \\
\hline 13 & 1 & 3 & 0.5 & 0.001 & 1.64 \\
\hline 14 & 3 & 2 & 0.3 & 0.007 & 1.15 \\
\hline 15 & 3 & 4 & 0.3 & 0.003 & 2.83 \\
\hline 16 & 1 & 3 & 0.5 & 0.005 & 1.11 \\
\hline 17 & 1 & 1 & 0.1 & 0.005 & 0.63 \\
\hline 18 & 5 & 1 & 0.1 & 0.001 & 2.48 \\
\hline 19 & 3 & 2 & 0.3 & 0.001 & 1.47 \\
\hline 20 & 5 & 3 & 0.5 & 0.005 & 1.7 \\
\hline 21 & 5 & 1 & 0.5 & 0.005 & 0.98 \\
\hline 22 & 3 & 2 & 0.7 & 0.003 & 1.4 \\
\hline 23 & 3 & 2 & 0.3 & 0.003 & 4.49 \\
\hline 24 & 3 & 2 & 0.3 & 0.003 & 4.4 \\
\hline 25 & -1 & 2 & 0.3 & 0.003 & 0 \\
\hline 26 & 3 & 2 & 0.3 & 0.003 & 3.84 \\
\hline 27 & 5 & 1 & 0.5 & 0.001 & 1.99 \\
\hline 28 & 3 & 2 & 0.3 & 0.003 & 4.63 \\
\hline 29 & 3 & 2 & -0.1 & 0.003 & 2.15 \\
\hline 30 & 7 & 2 & 0.3 & 0.003 & 2.37 \\
\hline
\end{tabular}

Tab. 2: Experimental design and corresponding results of rhamnolipid production in $(\mathrm{g} / \mathrm{L})$ under the influence of $\mathrm{X}_{1}$, $\mathrm{X}_{2}, \mathrm{X}_{3}$, and $\mathrm{X}_{4}$.The values of response $\left(\mathrm{Y}_{1}\right)$ were obtained after running experiments in triplicate.

Analysis of variance (ANOVA) test was used to find out the fitness of the experimental design. Results indicated an Fvalue of 16.90 predicting that our model was significant. Moreover, $P$-value $<0.0001$ of the model further validated the significance of the experimental procedure. The linear and cumulative interactions between the variables were ascertained by relevant $p$-values of the process variables (Table 3). It was noted that $X_{1}\left(\mathrm{NaNO}_{3}\right), X_{2}\left(\mathrm{~K}_{2} \mathrm{HPO}_{4}\right), X_{3}$ $\left(\mathrm{MgSO}_{4}\right), X_{4}\left(\mathrm{FeSO}_{4}\right), X_{1} \times X_{3}\left(\mathrm{NaNO}_{3} \times \mathrm{MgSO}_{4}\right)$ were identified as significant model terms (Table 3). The regression equation for the test model was:

$\mathrm{Y}_{1}=+4.42+0.56 \mathrm{X}_{1}+0.51 \mathrm{X}_{2}-0.27 \mathrm{X}_{3}-0.18 \mathrm{X}_{4}-0.21 \mathrm{X}_{1} \mathrm{X}_{3}$ $-0.16 \mathrm{X}_{2} \mathrm{X}_{3}-0.74 \mathrm{X}_{1}^{2}-0.65 \mathrm{X}_{2}^{2}-0.59 \mathrm{X}_{3}^{2}-0.71 \mathrm{X}_{4}^{2}$

Where $Y_{1}$ is the estimated response (rhamnolipid) and $X_{1}$, $\mathrm{X}_{2}, \mathrm{X}_{3}$, and $\mathrm{X}_{4}$ were coded factors for $\mathrm{NaNO}_{3}, \mathrm{KH}_{2} \mathrm{PO}_{4}$, $\mathrm{MgSO}_{4}$ and $\mathrm{FeSO}_{4}$, respectively.

The adequacy of the model was evaluated with reference to the coefficient of variance (C.V) and coefficient of regression $\left(\mathrm{R}^{2}\right)$. The C.V value of $14.6 \%$ indicates a high degree of precision and reliability of the experimental data (Table 3). Similarly, $\mathrm{R}^{2}$ value 0.94 , suggested that both predicted and experimental values were in close conformity to each other and $94 \%$ of the variability in the response can be explained by the model (Fig. 1). The adequate precision measures the signal to noise ratio which was $13.76 \%$ in case of present research indicating an adequate signal. The lack of fit was found to be non-significant which depicted that production of rhamnolipids can be further improved by selecting more closer ranges of nutritional parameters. The interactive effects of nutritional parameters on rhamnolipid production by $P$. aerugnosa was investigated by plotting response surface curves against any two independent variables while keeping other at the constant level.

The results revealed that $\mathrm{NaNO}_{3}$ has a notable (p-value $<0.0001$ ) effect on rhamnolipid production by $P$. aeruginosa (Table 3). The strain JQ showed variable metabolic responses under the effect of nitrate ions in the medium.

Table 3. ANOVA of Selected Model Terms for Rhamnolipid [Y $\mathbf{Y}_{1}$.

\begin{tabular}{|l|c|l|c|c|c|}
\hline Source & Sum of squares & Degree of freedom & Mean square & F-value & P-value \\
\hline Model & 52.43 & 10 & 5.24 & 38.81 & $<0.0001$ \\
$\mathrm{~A}-\mathrm{NaNO}_{3}$ & 7.48 & 1 & 7.48 & 55.38 & $<0.0001$ \\
$\mathrm{~B}-\mathrm{KH}_{2} \mathrm{PO}_{4}$ & 6.18 & 1 & 6.18 & 45.71 & $<0.0001$ \\
$\mathrm{C}-\mathrm{MgSO}_{4}$ & 1.69 & 1 & 1.69 & 12.48 & 0.0022 \\
$\mathrm{D}-\mathrm{FeSO}_{4}$ & 0.82 & 1 & 0.82 & 6.06 & 0.0236 \\
$\mathrm{AC}$ & 0.73 & 1 & 0.73 & 5.42 & 0.0310 \\
$\mathrm{~A}^{2}$ & 14.99 & 1 & 14.99 & 110.96 & $<0.0001$ \\
$\mathrm{~B}^{2}$ & 11.66 & 1 & 11.66 & 86.31 & $<0.0001$ \\
$\mathrm{C}^{2}$ & 9.59 & 1 & 9.59 & 70.98 & $<0.0001$ \\
$\mathrm{D}^{2}$ & 13.72 & 1 & 13.72 & 101.56 & $<0.0001$ \\
\hline
\end{tabular}

$\mathrm{R}^{2}=0.9533$, Adj. $\mathrm{R}^{2}=0.9288$, Coffcient of Varience $=16.22 \%$, Adeq Precision $=18.30$ 
Maximum biosurfactant yield was observed at $3.92 \mathrm{~g} / \mathrm{L}$ of $\mathrm{NaNO}_{3}$, a point at the center of response surface curve. Whereas, synthesis of rhamnolipids was negatively affected when the concentration of $\mathrm{NaNO}_{3}$ either increased or decreased from central reference point as indicated in (Fig. 2 A, B, C). Basically, role of nitrate has been already established in regulating biosurfactant production via activation of glutamine synthase pathway. Furthermore, inorganic nitrogen in the fermentation media facilitates expression of the aforesaid enzyme system through their transcriptional activators such as RpoN and $\sigma$ factor $(\sigma 54)$ (Chayabutra, et al., 2001; Totten et al., 1990). It has also been suggested that low carbon to nitrate ratio stimulates lipogenesis via glutamine synthase pathway leading to overproduction of rhamnolipid. In contrast, excessive nitrogen drives the metabolism towards protein synthesis. The results of the present findings are in allinece with some previous reports.

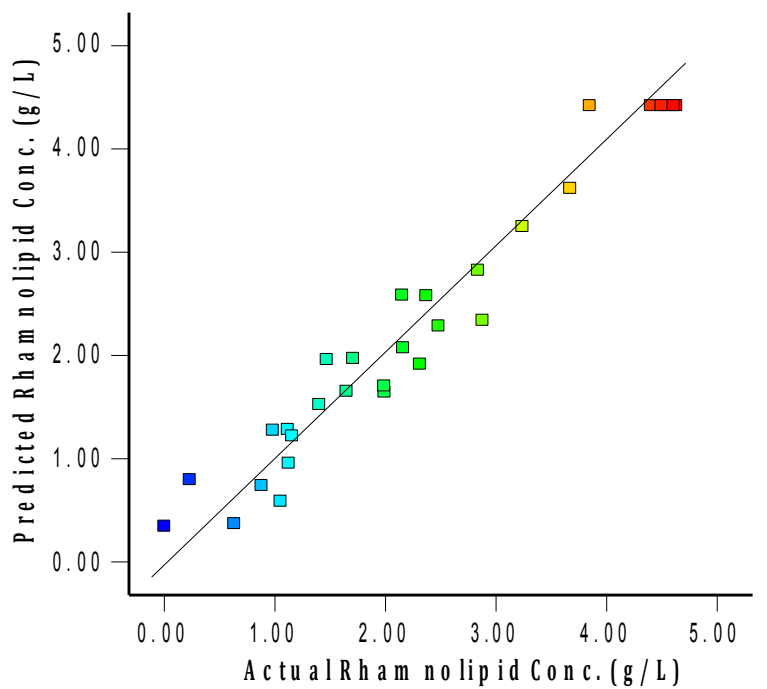

Figure 1. Predicted vs Actual Rhamnolipid Conc. (g/L).

Our results indicated that different Conc. of $\mathrm{KH}_{2} \mathrm{PO}_{4}$ was positively effecting $(p<0.0001)$ rhamnolipid production by $P$. aeruginosa JQ (Table 3 ). The optimum Conc. of $\mathrm{KH}_{2} \mathrm{PO}_{4}$ for highest rhamnolipid production was noted as $2.38 \mathrm{~g} / \mathrm{L}$. The production of rhamnolipid was decreased even at slight deviation from the peak area indicated in (Fig. 2 A, D, E). It was observed that production of rhamnolipid from strain JQ was improved significantly at low concentration of $\mathrm{KH}_{2} \mathrm{PO}_{4}$ in the medium. Phosphate limitation in culture media has been known to influence the expression of rhlR genes through various transcriptional activators such as Vfr, RhlR and $\sigma^{54}$ (Bazire et al., 2005). It could be suggested activation of RhlR genes under phosphate limitation may resulted in high yield of rhamnolipid by $P$. aeruginosa JQ. These results are in accordance with some previous reports which suggested a multi fold increase in biosurfactants production under phosphate -limited conditions (Chayabutra et al., 2001; Abalos et al., 2002).

Magnesium is essential micronutrient participate in various enzyme catalyzed reactions such as transfer of phosphate and pyruvate metabolism. $\mathrm{MgSO}_{4}$ was shown to be a significant model term with p-value of 0.0022 (Table 3). The maximum rhamnolipid was predicted at the center point of response surface plots corresponds to $0.26 \mathrm{~g} / \mathrm{L}$ of the $\mathrm{MgSO}_{4}$ (Fig. 2 B, D, F). Less yield of rhamnolipid was recorded while moving beyond this peak area indicating that not only the low concentration of $\mathrm{MgSO}_{4}$ but also its ratio plays important role in rhamnolipid biosynthesis. It has been previously observed that suboptimal level of $\mathrm{Mg}^{++}$effects not only the growth but also restrict activation of various enzymes involved in metabolic pathway associated with rhamnolipid biosynthesis. The results of present research are comparable with some previous research findings which suggested that $\mathrm{Mg}^{++}$limitation in the media improve rhamnolipid production from $P$. aeruginosa (Roldan-Carrillo et al., 2011).

Iron is a key micronutrient for energy deriving metabolic pathways such as oxidative phosporylation and a critical parameter for the production of biosurfactants from different bacteria. It was noted that iron was a significant model term (p-value 0.023) for rhamnolipid production (Table 3). The amount of $\mathrm{FeSo}_{4}$ pertaining to the highest rhamnolipid production was $0.028 \mathrm{~g} / \mathrm{L}$ predicted at the middle of response surface plots (Fig. 2 C,E,F). The fluctuation from this optimum point hampered the production of rhamnolipid by $P$. aeruginosa. It has been recognized that an inverse relation exists between transcription of rhlAB gene and concentration of iron in the media (Deziel et al., 2003; Glick et al., 2010). Furthermore, limitation of iron has also been associated with stimulation of lasIR and rhllR genes that increase production of rhamnolipid (Bollinger et al., 2001; Duan and Surette, 2007). Our results are in conformity with the findings of (Persson et al., 1990) indicated the dependency of rhamnolipid biosynthesis under restricted iron conditions.

The cumulative interaction between $\mathrm{NaNO}_{3}$ and $\mathrm{MgSO}_{4}$ was found to be significant while all other interactions were of less significance in present study (Table 3). The joint effect of $\mathrm{NaNO}_{3} \times \mathrm{MgSO} 4$ is shown in the (Fig. 2 B). The amount of biosurfactant was gradually increased with the increase in $\mathrm{NaNO}_{3}$ and $\mathrm{MgSO}_{4}$ concentrations and reached at final optimal values of $3.92 \mathrm{~g} / \mathrm{L}$ and $0.26 \mathrm{~g} / \mathrm{L}$, respectively. However, at further increase in the concentrations of these salts biosurfactant production was negatively affected. The findings of present research suggested that not only the concentration but the relative proportion of each media components affects the cellular productivity of rhamnolipid. It has been described frequently in the literature that low $\mathrm{C}: \mathrm{N}$, high $\mathrm{C}: \mathrm{P}$ and high $\mathrm{C}: \mathrm{Fe}$ ratios favor the production of biosurfactant from different bacterial strains including $P$. 


\section{Production of Rhamnolipid}

aeruginosa (Makkar and Cameotra, 2002; Amezcua-Vega et al., 2007; Kumar et al., 2012). Therefore, appropriate ratios of media contents should be investigated for making bioprocess economically more productive.

The optimum concentration of the media components were predicted as $3.92 \mathrm{~g} / \mathrm{L} \mathrm{NaNO}_{3}, 2.73 \mathrm{~g} / \mathrm{L} \mathrm{K}_{2} \mathrm{HPO}_{4}, 0.23 \mathrm{~g} / \mathrm{L}$ $\mathrm{MgSO}_{4}$ and $0.0028 \mathrm{~g} / \mathrm{L} \mathrm{FeSO}_{4}$. These values were obtained by moving towards the center of the contour plot and validated by performing a conformity experiment in triplicate. In conclusion, $5.67 \mathrm{~g} / \mathrm{L}$ of the rhamnolipid was produced under these reaction conditions leading a 2 fold increase in yeild as compared to unoptimized media.

\section{REFERENCES}

Abalos, A., F. Maximo, M.A. Manresa and J. Bastida. 2002. Utilization of response surface methodology to optimize the culture media for the production of rhamnolipids by Pseudomonas aeruginosa AT10. J. Chem. Technol. Biotechnol. 77:777-784.

Amezcua-Vega, C.A., P.H.M. Varaldo and F. Garcia. 2007. Effect of culture conditions on fatty acids composition of a biosurfactant produced by Candida ingens and changes of surface tension of culture media. Biores. Technol. 98: 237-240.

Banat, I.M., A. Franzetti, I. Gandolfi, G. Bestetti, M.G. Martinotti, L. Fracchia, T.J. Smyth and R. Marchant. 2010. Microbial biosurfactants production, applications and future potential. Appl. Microbiol. Biotechnol. $87: 427-444$.

Bazire, A., A. Dheilly, F. Diab, D. Morin, M. Jebbar, D. Haras and A. Dufour. 2005. Osmotic stress and phosphate limitation alter production of cell-to-cell signal molecules and rhamnolipid biosurfactant by Pseudomonas aeruginosa. FEMS Microbiol. Lett. 253:125-131.

Bollinger, N., D.J. Hassett, B.H. Iglewski, J.W. Costerton and T.R. McDermott. 2001. Gene expression in Pseudomonas aeruginosa: evidence of iron over ride effects on quorum sensing and biofilm specific gene regulation. J. Bacteriol. 183:1990-1996.

Burns, C.J., L.J. McIntosh, P.J. Mink, A.M. Jurek and A.A. Li. 2013. Pesticide exposure and neurodevelopmental outcomes: review of the epidemiologic and animal studies. J. Toxicol. Environ. Health B Crit. Rev. 16:127283.

Cameotra, S.S., R.S. Makkar, J. Kaur and S.K. Mehta. 2010. Synthesis of biosurfactants and their advantages to microorganisms and mankind. Adv. Exp. Med. Biol. 672:261-280.

Chandrasekaran, E.V and J.N. BeMiller. 1980. Constituent analysis of glycosaminoglycans. In: R.L. Whistler and J.N. Bemiller (eds.), Methods in Carbohydrate Chemistry. Academic Press, New York.
Chayabutra, C., J. Wu and L. Ju. 2001. Rhamnolipid production by Pseudomonas aeruginosa under denitrification: Effects of limiting nutrients and carbon substrates. Biotechnol. Bioeng. 72:25-33.

Chen, S.Y., W.B. Lu, Y.H. Wei, W.M. Chen and J.S. Chang. 2007. Improved production of biosurfactant with newly isolated Pseudomonas aeruginosa S2. Biotechnol. Prog. 23:661-666.

Das, P., S. Mukherjee, C. Sivapathasekaran and R. Sen. 2010. Microbial surfactants of marine origin: Potentials and prospects. Adv. Exp. Med. Biol. 672:88-101.

Deleu, M. and M. Paquot. 2004. From renewable vegetables resources to microorganisms: New trends in surfactant. CR Chimie. 7:641-646.

Deziel, E.F., S. Lepine, R. Milot and J. Villemur. 2003. rhlA is required for the production of a novel biosurfactant promoting swarming motility in Pseudomonas aeruginosa: 3-(3-hydroxyalkanoyloxy) alkanoic acids (HAAs), the precursors of rhamnolipids. Microbiology 149:2005-2013.

Duan, K. and M.G. Surette. 2007. Environmental regulation of Pseudomonas aeruginosa PAO1 Las and

Gilmour, S.G. 2006. Response surface designs for experiments in bioprocessing. Biometrics 62:323-331.

Glick, R., C. Gilmour, J. Tremblay, S. Satanower, O. Avidan, E. De'ziel, E.P. Greenberg, K. Poole and E. Banin. 2010. Increase in rhamnolipid synthesis under iron-limiting conditions influences surface motility and biofilm formation in Pseudomonas aeruginosa. J. Bacteriol. 192:2973-2980.

Gudina, E. J., A.I. Rodrigues, E. Alves, M.R. Domingues, J. A. Teixeira and L. R. Rodrigues. 2015. Bioconversion of agro-industrial by-products in rhamnolipids toward applications in enhanced oil recovery and bioremediation. Bioresour. Technol. 177: 87-93.

Kammoun, R., B. Naili and S. Bejar. 2008. Application of a statistical design to the optimization of parameters and culture medium for a-amylase production by Aspergillus oryzae CBS 819.72 grown on gruel (wheat grinding byproduct). Bioresour. Technol. 99:5602-5609.

Kiran, G.S., J. Selvin, A. Manilal and S. Sujith. 2011. Biosurfactants as green stabilizers for the biological synthesis of nanoparticles. Crit. Rev. Biotechnol. 31:354-364.

Kumar, C.G., S.K. Mamidyala, P. Sujitha, H. Muluka and S. Akkenapally. 2012. Evaluation of critical nutritional parameters and their significance in the production of rhamnolipid biosurfactants from Pseudomonas aeruginosa BS-161R. Biotechnol. Prog. 28:1507-1516.

Makkar, R.S and S.S. Cameotra. 2002. Effects of various nutritional supplements on biosurfactant production by a strain of Bacillus subtilis at $45^{\circ} \mathrm{C}$. J. Surf. Detergents 5:11-17. 
Nitschke, M., S.G. Costa, R. Haddad, L.A. Goncalves, M.N. Eberlin and J. Contiero. 2005. Oil wastes as unconventional substrates for rhamnolipid biosurfactant production by Pseudomonas aeruginosa LBI. Biotechnol. Prog. 21:1562-1566.

Pacwa-Plociniczak, P.G.A., Z. Piotrowska-Seget and S.S. Cameotra. 2011. Environmental applications of biosurfactants: recent advances. Int. J. Mol. Sci. 12:633-654.

Persson, A. and G. Molin, N. Anderson and J. Sjoholm. 1990. Biosurfactant yields and nutrient consumption of Pseudomonas fluorescens 378 studied in a microcomputer controlled multifermentation system. Biotechnol. Bioeng. 36: 252-255.

Roldan-Carrillo, T., X. Martinez-Garcia, I. Zapata-Penasco, G. Castorena-Cortes, J. Reyes-Avila, M. MayolCastillo and P. Olguin-Lora. 2011. Evaluation of the effect of nutrient ratios on biosurfactant production by Serratia marcescens using a Box-Behnken design. Colloids Surf. B: Biointerfaces 86:384-389.

Rocha e Silva, N.M.P., R.D Rufina, J.M. Luna, V.A. Santos and L.A. Saurbbo. 2014. Screening of Pseudomonas species for biosurfactant production using low-cost substrate. Biocatalysis and Agricultural Biotechnology Volume 3, Issue 2, April 2014, Pages 132-139.

Ron, E.Z. and E. Rosenberg. 2011. Natural roles in biosurfactants. Environ. Microbiol. 3:229-236.

Sachdev, D.P. and S.S. Cameotra. 2013. Biosurfactants in agriculture. Appl. Microbiol. Biotechnol. 97:1005-1016.

Sha, R., L. Jiang, Q. Meng, G. Zhang and Z. Song. 2011. Producing cell-free culture broth of rhamnolipids as a cost-effective fungicide against plant pathogens. J. Basic Microbiol. 52:458-466.

Totten, P.A., J.C. Lara and S. Lory. 1990. The rpoN gene product of Pseudomonas aeruginosa is required for expression of diverse genes, including the flagellin gene. J. Bacteriol. 172:389-396.

Vatsa, P., L. Sanchez, C. Clement, F. Baillieul and S. Dorey. 2010. Rhamnolipid Biosurfactants as New Players in Animal and Plant Defense against Microbes. Int. J. Mol. Sci. 11(12): 5095-5108.

Yan. F., S. Xu, Y. Chen and X. Zheng. 2014. Effect of rhamnolipids on Rhodotorula glutinis biocontrol of Alternaria alternata infection in cherry tomato fruit. Postharvest Biol. Technol. 97: 32-35 